\title{
The Study on the Development Mode of Ningxia Rural Grass-roots
}

\section{Economic Organizations}

\author{
Zhang Miao ${ }^{1, a}$, JinZhuoWen ${ }^{2, b}$ \\ ${ }^{1,2}$ Ningxia polytechnic(Ningxia radio and TV University), Ningxia, Yinchuan,750021 China \\ a,b1343222040@qq.com
}

Keywords: Ningxia; rural grass-roots; economic mode; development mode; study

\begin{abstract}
.
As a backward area in China, how to improve economic level of farmers is a key to be considered. With the constant development of social market economy, Ningxia rural areas need to enlarge support for financial institutions and enter into the recycling economic development mode based on advantages of developing economic cooperation mode, for the sake of promoting rapid economic development. This is the long-term policy of developing economy in Ningxia rural areas.
\end{abstract}

\section{Introduction}

Ningxia is a traditional agricultural province in the west area. It is an underdeveloped minority area. In order to promote comprehensive development of grass-roots economic organizations in rural areas, increase farmers' incomes, improve living standards of farmers in Ningxia rural areas, and make a great contribution to comprehensive and harmonious development in economic society, it is extremely necessary to reinforce the study on the development mode of economic organizations.

\section{Financial Support and Econometric Model of Ningxia Rural Grass-roots Economic Development}

As selecting variables, economic development finally will be reflected in regional GDP, thus Ningxia GDP is used as the dependent variable. Save in financial institutions, debits in financial institutions, financing amount in capital market(especially for stock), foreign capital and government revenue have the decisive influences on GDP, so they are used as explaining variables. The relationship between investment combination of financial elements and possible GDP output quantity is studied. In order to ensure specific economic significance for parameters and be convenient for analysis, C-D production function is specially selected. Assuming that there is such a relationship between financial elements:

$$
C D P=\alpha(S)^{\mathrm{a} 1}(B)^{\mathrm{a} 2}(S T)^{\mathrm{a} 3}(F C)^{\mathrm{a} 4}(G)^{\mathrm{a} 5}
$$

In order to eliminate order of magnitude and obtain the mean GDP output elasticity, logarithm transformation is conducted on both ends of equations:

$$
\log (G D P)=\mathrm{a}_{0}+\mathrm{a}_{1} \log (S)+\mathrm{a}_{2} \log (B)+\mathrm{a}_{3} \log (S T)+\mathrm{a}_{4} \log (F C)+\mathrm{a}_{5} \log (G)
$$

In the formula, GDP standards for gross domestic product in Ningxia; $\mathrm{S}$ is the deposit in financial institutions; B is the loan amount of financial institutions; ST is the financing amount in listed 
companies(stock financing amount); FC is the actual utilization of foreign capital funds; $G$ is financial revenue in Ningxia; $\mathrm{a}_{1}, \mathrm{a}_{2}, \mathrm{a}_{3}, \mathrm{a}_{4}, \mathrm{a}_{5}$ are output elasticity of elements. $\mathrm{a}_{0}$ is constant, including industrial structural adjustment and human resource configuration, etc.

By looking by Ningxia Yearbook and Ningxia Statistical Yearbook, the relevant data of corresponding financial operation are acquired. Least square method is used to do regression analysis on Ningxia DGP, so as to acquire the corresponding estimation results. Then, results are conducted econometric verification, finding out some inertia in economic development. For example, GDP and time sequence of loan granting have some cyclical movement. Successive observed value has some interdependence, resulting in phenomenon of serial correlation. By summarizing Ningxia financial support and economic development mode, it finds that DW value is close to 2, passing 5\% of DW value verification. The equation has no first-order correlation, as shown in Figure 1:

Fig.1: Non-order Phenomenon Diagram of Ningxia Financial Support and Measurement Model of Rural Grass-roots Economic Development

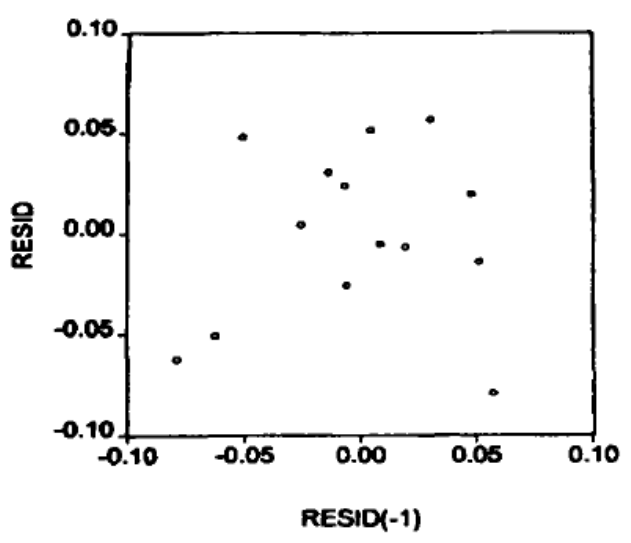

It can be observed from Figure 1 that scatter diagram distribution of et and e(t-1) has no discipline. There is no sequence correlation. After further study, it finds that economic backwardness in Ningxia rural areas have some influence factors, including shortage of effective channels to translate savings into investment, underdeveloped capital market, unreasonable utilization of foreign capital, and scientific arrangement of financial incomes, etc.

\section{Recycling Economic Development Mode Based on Ecological Efficiency}

The study on the recycling economic development mode is the core content in the current sustainable development study and correlative decision of the government. In recycling economy, systematic opinions are applied to view human activities, hoping to improve utilization efficiency of resource energy and reduce environment pollution by adjusting human behaviors, especially for cyclic utilization of resources and energy stair, thus society, economy, resources and environment can reach the win-win state. Ecological efficiency is the suitable measurement of recycling economy. It is the comprehensive representation index of resource energy efficiency and environmental efficiency.

At present, the concept of ecological efficiency defined by WBCSD is widely accepted. In other words, by providing services and commodities with price advantages, it meets high-quality life demands and reduces the influences of life cycle on environment to be consistent with estimated bearing capacity of the earth. To be simple, it means to minimize value maximization. The formula 
can be expressed as follows:

$$
\text { Ecological Efficiency }=\frac{\text { product or service value }}{\text { resource consumption or environment influences }}
$$

In the formula(3), resource consumption or environmental influence stands for ecological load. The corresponding ecological efficiency also can be divided into resource efficiency and environmental efficiency. If the ecological efficiency is the specific value between social service quantity and ecological load growth rate, it is equal to the reciprocal of elastic coefficient, it is a dimensionless expression, marked as $\mathrm{R}$ and $\mathrm{P}$, respectively.

$$
\begin{gathered}
\mathrm{R}=\frac{\alpha \text { (GDP or population growth factor) }}{\beta \text { (resources and energy consumption growth factor) }} \\
P=\frac{-b \pm \sqrt{b^{2}-4 a c} \alpha^{\prime} \text { (GDP or industrial growth factor) }}{\beta \text { (environmental and pollutant discharge growth factor) }}
\end{gathered}
$$

Resource efficiency R and environmental efficiency P model stand for ecological efficiency of regional substance metabolism from the perspective of source circulation(reduce consumption of native resources) and end circulation(reduction of pollutants). By combining with research achievements, it can construct the ecological efficiency measurement and evaluation model of circular economic mode. On the basis of standardizing environment efficiency and resource efficiency, the curve $E=\sqrt{\mathrm{x}^{2}+\mathrm{y}^{2}}$ and straight line constitute the measurement model as shown in Figure 2:

Fig. 2 Ecological Efficiency Measurement and Evaluation Mode of Circular Economic Mode

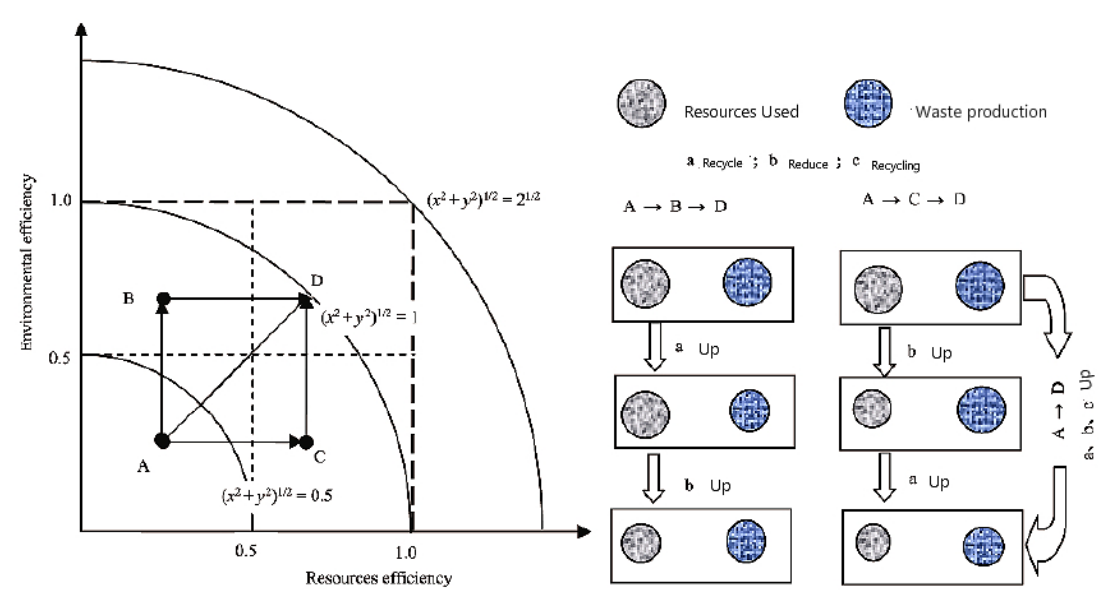

Where the curve $E=\sqrt{\mathrm{x}^{2}+\mathrm{y}^{2}}$ stands for the tendency of ecological efficiency; the further origin from the curve is, the higher ecological efficiency E will be. After standardization treatment, the value of environment efficiency and resource efficiency is between [0,1]. Ecological efficiency $\mathrm{E}$ is located between $[0, \sqrt{2}]$, the square in $[0,1]$ is divided into four areas by the straight lines $\mathrm{x}=0.5$ 
and $\mathrm{y}=0.5$, including, $\mathrm{A}, \mathrm{B}, \mathrm{C}$ and $\mathrm{D}$. It conceptually represents the recycling economic development pattern in the region.

Indicators relating to ecological efficiency mainly select GDP as numerator to stand for social or service value. energy consumption, water consumption, land construction are used as denominators, showing the resource consumption degree. GOD discharge, $\mathrm{SO}_{2}$ discharge, solid waste discharge stand for degree of environmental influences. By combining with formula (4) and (5), the resource efficiency and environment efficiency are calculated. The formula $E=\sqrt{\mathrm{x}^{2}+\mathrm{y}^{2}}$ are used to calculate ecological efficiency. For this reason, formula(4) and (5) can be specifically expressed as formula(6) and (7);

$R$ $=\frac{\text { GDP in the } \mathrm{n}+1 \text { th year } / \mathrm{GDP} \text { in the nth year }}{\text { resource consumption in the } \mathrm{n}+1 \text { th year/resource consumption in the nth year }}(6)$ $P=\frac{\text { GDP in the } \mathrm{n}+1 \text { th year } / \mathrm{GDP} \text { in the nth year }}{\text { pollutant discharge in the } \mathrm{n}+1 \text { th year/pollutant discharge in the nth year }}$

According to the requirements of conceptual model of ecological efficiency, the value of resource efficiency and environment efficiency belongs to [0,1]. As a result, it must conduct standardization treatment. MIN-MAX standardization method is used. The above-mentioned indicators belong to positive indicators, and the standardization method is shown in formula(8).

$$
Z_{\mathrm{i}}=\frac{X_{\mathrm{i}}-\min \left(X_{\mathrm{i}}\right)}{\max \left(X_{\mathrm{i}}\right)-\min \left(X_{\mathrm{i}}\right)}
$$

Where, $\mathrm{Z}$ is the standardized value. $\mathrm{X}_{\mathrm{i}}$ is the indicator property. After standardization treatment, the mean standardized value of resource efficiency and environmental efficiency over years in Ningxia rural areas is obtained. Then, according to formula $E=\sqrt{\mathrm{x}^{2}+\mathrm{y}^{2}}$, ecological efficiency can be calculated.

By further in-depth study, it finds that ecological efficiency changes in Ningxia rural areas probably experiences the traditional development mode, end governmental mode and circular economic mode. This is consistent with the traditional economic development track in China. It also shows that development law of environmental Kuznets' curve, namely harmlessness $\rightarrow$ minimization $\rightarrow$ resource, showing that Ningxia rural areas should reinforce environmental pollutant governance. In addition to reinforce environment supervision and protective strength, it must further improve the recycling level of waste reclamation, so as to improve ecological resource efficiency and speed up the process for Ningxia to enter into recycling economic development mode.

\section{The Analysis about the Ningxia Rural Cooperative Economic Organization}

The Ningxia Rural Cooperative Organization was presented in the end of 1980s. Afterwards, it entered into the rapid development mode rapidly. According to relevant data statistics, in 2000, there were less than 100 Ningxia Rural Cooperative Economic Organizations. Until the first half of 
2006, it had 676 organizations. Until the end of 2006, there were a total of 762, absorbing 128300 members and driving 543300 members, accounting for $14 \%$ and $57 \%$ among total agriculture. 64.043 million yuan of total capital was obtained. It basically got involved in every field in rural economic development, including plantation, fishery, animal husbandry and agricultural machinery. The fixed capital reached 404 million yuan. Actual operation incomes reached 235 million yuan. profits were 30.98 million yuan. Total capital dividend was 1.93 million yuan. Until 2007, the number of rural cooperative economic organizations was increased to 1047 to improve living standard of Ningxia rural residents.

In recent years, it develops an increasingly important role in farmers accessing to the market, promoting the connection between the market and households, and solving difficult sales of farmers. In addition, it also realizes a win-win result between professional cooperative economic organizations and farmers. It also can improve comprehensive productive ability in Ningxia rural areas constantly and adjust agricultural structure constantly, so that it tends to be reasonable, enlarge manpower, property, and financial investment strength in special advantage industry, improve processing rate of agricultural products, utilize original resources in Ningxia rural areas, and develop agricultural mechanization, so as to ensure development of Ningxia farmers' economic incomes.

\section{Conclusions}

Of course, in order to follow up with social economic development level, Ningxia rural grass-roots not only should continue developing cooperative economic organizational form, but also should enlarge financial institutions' support for Ningxia rural economic development, so that it can step on the recycling economic development model, promote the development of Ningxia rural grass-roots economy effectively and create the greater economic benefits for farmers.

\section{Acknowledgments}

(Ningxia science and technology department science and technology support project "Ningxia rural grassroots economic organization development model", item number: 2015BY140)

\section{References}

[1] Wu Sufang, Developmental Mode Selection of Ningxia Rural Cooperative Economic Organizations[J], Journal of Anhui School of Administration, 2008, 24(4): 76-79;

[2] Lu Jun and He Jiming, Development Status of Ningxia Rural Professional Cooperative Economic Organizations and Measures[J], Agricultural Science and Information, 2009(23): 6-7;

[3] Sun Yinchun, the Study on Ningxia Rural Financial Development[D], Northwest Agriculture \& Forestry University, 2016;

[4] Huang Heping, Jiangxi Recycling Economic Development Mode Based on Ecological Efficiency[J], Ecological Journal, 2015, 35(9): 2894-2901;

[5] Li Junping, Measures on Promoting Ningxia Rural Economic Development in New Period[J], Management Observation, 2012(32): 136-138;

[6] Wang Huifang, Development Status and Relationship Study between Ningxia Rural Finance and Economy[J], Guide to Business, 2015(19): 21-22;

[7] Li Yujun, Contradictions and Challenges Faced by Ningxia Agricultural Rural Economy[J], 
Beijing Agriculture, 2015(34): 180-181;

[8] Zhang Jing, Interactive Development Study on Ningxia Rural Finance and Economy[D], Minzu University of China, 2012 